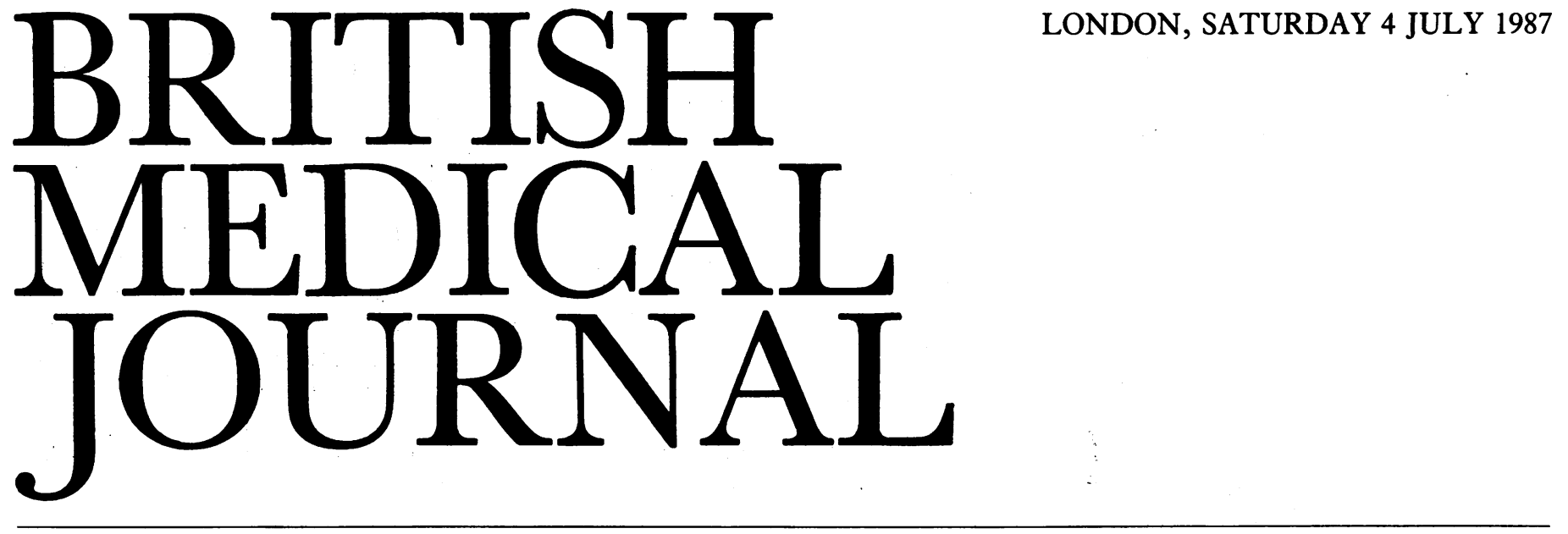

\title{
The OPCS: many (more) happy returns?
}

\begin{abstract}
The Marriages, Births and Deaths, produce important effects; are influenced by the prosperity of the country; and express the hopes, fears, enjoyments, and sufferings of the people living in the agricultural, mining, and manufacturing districts; on the coasts and in the interior of the country; in the narrow, tortuous streets of cities, and in the sunshine and showers on hill sides and moors.... As they are facts, and are expressed numerically, they admit of no exaggeration; while they correct the fallacy of judging of the state of a great and various kingdom, either from the field of one man's experiencefrom his own parish and county-or from vague accidental prejudiced representations. The present arrangement will show, at short intervals, how many marry, how many are born, and how many die in England; and will thus appear in time to enable the public and the Legislature to take the indications which the returns may furnish into account in the conduct of affairs. ${ }^{1}$
\end{abstract}

This week the registration of marriages, births, and deaths by the General Register Office is 150 years old. Born in the first days of Queen Victoria's reign, the General Register Office was a true child of its time, imbued with the best Victorian values. It was practical, humane, and confident that problems could be solved once they had been identified. Armed with the office's statistics linking mortality to living conditions, the nineteenth century sanitary reformers moved in on the inner cities and cleaned them up, notching up some of the most spectacular public health successes ever. Since then the data collected by the General Register Office have become ever more detailed: in addition to its former functions of registration and census taking, the office now compiles statistics on hospital inpatients and patients seen in general practice, and registers are kept of the incidence of cancer and congenital malformations.

With marriage to the Social Survey Department in 1970 came a change in name- to the Office of Population Censuses and Surveys - and a particularly fruitful decade of work. The decennial supplement on occupational mortality based on the 1971 census $^{2}$ and the study it sparked off, the Black report, ${ }^{3}$ are now regarded as landmarks in social inequality and health, internationally if not in Britain. The use of computers has permitted linkage studies that combine information collected from different sources. The best known of these is the longitudinal study of a $1 \%$ sample of respondents to the 1971 census, whose census data are being linked to data on subsequent births, cancer registrations, long term admissions to psychiatric hospital, emigrations, and deaths. According to Sir Donald Acheson, chief medical officer at the Department of Health and Social Security, this study may prove to be "the most significant development in the field of routine social and medical statistics since universal registration of births and deaths became mandatory in 1837."

By contrast the 1980s have been a lean time for the Office of Population Censuses and Surveys: it has been subject to a series of debilitating reviews, cuts in funding, and threats of privatisation. All this has been done to ensure value for money for the taxpayer, although there are darker undercurrents. Last year's machinery of government report (which was officially confirmed to be under way only when it was leaked to the press) recommended several administrative measures "to clarify the relationship between OPCS and Ministers." Taken with recent staff changes it would seem that the arm's length relationship of the Office of Population Censuses and Surveys with the government may be in jeopardy, for the first time in 150 years.

In the registrar general's optimistic statement of 1849 quoted above, arguing that hard facts are necessary for an informed debate, the public was placed before the legislature (and if the public had not had access to the General Register Office's statistics the pressure for public health reform might never have come about). He must have realised that the public and the legislature would sometimes be in conflict, but would he have had any inkling that today's solution to this problem would be to write the public out of the script completely? Gone is the dilemma of an employee of the Office of Population Censuses and Surveys having to choose between betraying the public or the legislature; the former is now perceived by the government as a government service. No longer is it to be supported as the independent source of facts about health and society. The collection of data which may some time be used against a government is no longer considered value for money. Thus the treatment of social class and health in the most recent decennial supplement was perfunctory ${ }^{67}$ and the future of the longitudinal survey is in doubt. There has been a change in what data have been collected and in the form and timing of their release. Standards of intelligibility for the non-specialist reader (the taxpayer) have reached an all time low. ${ }^{8}$

So is this terminal decline or just a severe midlife crisis? It is not only charity amid the birthday celebrations to hope that it is a midlife crisis. There is still much to be done to uncover 
the social determinants of ill health, and we need the help of the Office of Population Censuses and Surveys, just as much as the Victorians needed its forerunner's help 150 years ago.

TONY DELAMOTHE

Assistant editor, $B M F$

1 General Register Office. Quarterly retum. London: HMSO, 1849.

2 Office of Population Censuses and Surveys. Occupational mortality. Decennial supplement England and Wales 1970-2. London: HMSO, 1978.

3 Department of Health and Social Security. Inequalities in health: report of a research working group. London: DHSS, 1980. (Black report.)

4 Baldwin JA, Acheson ED, Graham WJ, eds. Textbook of medical record linkage. Oxford: Oxford University Press, 1978:8.

5 Thatcher M. Parliamentary written answer. House of Commons Official Report (Hansard) 1986 November 16;105:col 86. (No 5.)

6 Office of Population Censuses and Surveys. Occupational mortality. Decennial supplement Great Britain 1979-80, 1982-83. London: HMSO, 1986.

7 Anonymous. Lies, damned lies, and suppressed statistics. Br Med $\mathrm{f}$ 1986;293:349-50.

8 Office of Population Censuses and Surveys. Cancer incidence and mortality in the vicinity of nuclear installations, England and Wales, 1959-1980. London: HMSO, 1987.

\section{Measles must go and with it rubella}

In Britain the public and many doctors still fail to realise the importance of preventing measles by vaccination. Perhaps the message that among the $90000-100000$ cases notified each year $10 \%$ of patients experience complications ${ }^{1}$ is insufficiently emphasised. Each year about $90-100$ patients develop measles induced encephalitis, of whom $15 \%$ die and $25 \%$ have residual sequelae. ${ }^{2}$

Measles often kills children with malignant disease, which is unnecessary and tragic as over $60 \%$ of children with acute lymphoblastic leukaemia now survive free from disease for at least five years. ${ }^{3}$ Infection, particularly measles, is responsible for the deaths of most who succumb during remission from disease not associated with leukaemia. Two studies, one from Newcastle ( $p$ 15) and the other from four centres ( $p$ 19), emphasise the severity of measles in children with malignant disease, mostly acute lymphatic leukaemia. Both draw attention to the high mortality and the difficulty in establishing a clinical diagnosis as the rash may be absent, mild, or atypical. In the four centre study measles killed a third of 51 children who died in first remission; indeed, 15 of 18 children who developed measles died. In contrast, fewer (27\%) died in the Newcastle study, probably because the authors used a rapid and sensitive immunofluorescence technique for early diagnosis; they probably identified patients with milder disease, many of whom survived. Normal human immunoglobulin usually prevents or attenuates measles if given within 72 hours of contact. Although only one of six children given this preparation died in Newcastle, it is disquieting that the four centre study reported three deaths despite normal human immunoglobulin being given promptly.

Most children develop acute lymphoblastic leukaemia after the age at which measles vaccination should have been given. Children who are still susceptible to measles after developing malignant disease cannot be given live vaccines. It is possible, however, that the further attenuated measles vaccines that are now in general use might be well tolerated by patients in remission from acute lymphoblastic leukaemia; an attenuated vaccine protects such patients from chickenpox. ${ }^{4}$ Japanese workers have shown that one of their attenuated measles vaccines (CAM70) is well tolerated and induces persistent antibody responses in children in remission from acute lymphoblastic leukaemia, but only a few patients were vaccinated and no evidence was available on protective efficacy. ${ }^{5}$ In the United States a few children and young adults with asymptomatic infection with human immunodeficiency virus (HIV) have received live vaccines without any adverse outcome, but these patients were probably less immunocompromised than children who have recently been treated for acute lymphoblastic leukaemia. The United States advisory committee on immunisation practices recommends that asymptomatic children infected with HIV may be vaccinated with a combined measles, mumps, and rubella vaccine. ${ }^{67}$

None of the patients who developed measles in the Newcastle study had a history of naturally acquired measles or measles vaccination, but three patients with fatal measles in the four centre study had had naturally acquired measles or measles vaccination. In the United States there is practically no opportunity for children with leukaemia to be exposed to measles. Legislation ensures that children are vaccinated against measles, rubella, polio, and diphtheria before entering school in all states, and for tetanus, pertussis, and mumps in most states. ${ }^{8}$ Thus in the United States almost all children will have been vaccinated against measles before developing leukaemia. Since 1971 measles vaccine has been given successfully with mumps and rubella vaccines as a combined vaccine. Measles, mumps, and rubella are now rare in the United States: about $1500-6000$ cases of measles are notified each year, most in children of preschool age living in deprived urban areas.

Any doubt about the long term efficacy of measles vaccine should be dispelled by the results of the 21 year follow up of the Medical Research Council's measles vaccine trial: those vaccinated have maintained a high order of protection compared with those not vaccinated ( $p$ 22). A few cases of measles were reported among those vaccinated: some may have been incorrectly diagnosed and others the result of vaccine failure. Vaccine stabilisers will, however, make vaccine failure very rare in future.

The rate of uptake of measles vaccine among infants in England and Wales is now $68 \%$, which is comparable with the uptake rate for pertussis vaccine but well below the $85 \%$ for diphtheria, pertussis, and tetanus (DPT) and polio, vaccines. In many districts, not all in urban deprived areas, the proportion is well below $68 \%$. In contrast, some districts with high unemployment rates, such as north west Durham and Bolton, have vaccinated $75-80 \%$ of infants against measles (M T Begg, personal communication). Can Britain without legislation meet the World Health Organisation's target in Europe of a $90 \%$ uptake rate for DPT, tetanus, polio, rubella, and measles vaccines?" The aim is to eradicate these diseases by the year 2000. Many European countries, including the Netherlands and Nordic countries, are already approaching this target without having to resort to compulsion. (World Health Organisation European Advisory Group circulated report on expanded programme of immunisation, 1986.)

In an attempt to achieve this goal the Department of Health and Social Security has now asked each health district to nominate a person responsible for its immunisation performance. District health authorities will be accountable through the review system for their performance. The National Health Service Management Board should also take an active interest in improving immunisation rates. It was 